\title{
3 Research Square

\section{Fetal pulmonary valvuloplasty in fetuses with right ventricular outflow tract obstructive disease: experience and outcome of the first five cases in China}

Chengcheng Pang ( $\sim$ pcc850117@sina.com )

Guangdong General Hospital https://orcid.org/0000-0001-9270-9102

Wei Pan

Guangdong General Hospital

Zhiwei Zhang

Guangdong General Hospital

Chengbin Zhou

Guangdong General Hospital

yufan Li

Guangdong General Hospital

Xu Zhang

Guangdong General Hospital

Fengzhen Han

Guangdong General Hospital

Yunxia Sun

Guangdong General Hospital

Cheng Wang

Guangdong General Hospital

Jian Zhuang

Guangdong General Hospital

Research article

Keywords: Fetus; Echocardiography; Pulmonary valve stenosis; Pulmonary atresia; Balloon dilation

Posted Date: September 17th, 2019

DOl: https://doi.org/10.21203/rs.2.13607/v1

License: (c) (i) This work is licensed under a Creative Commons Attribution 4.0 International License.

Read Full License 
Version of Record: A version of this preprint was published at Pediatric Cardiology on October 22nd, 2020. See the published version at https://doi.org/10.1007/s00246-020-02488-8. 


\section{Abstract}

Background To report our initial experience of fetal pulmonary valvuloplasty (FPV) in fetuses with pulmonary atresia with intact ventricular septum (PA/IVS) or critical pulmonary stenosis (CPS), including the experiences of case selection, technical feasibility, post-FPV effects in utero and the postnatal outcome. Methods Two cases with fetal PA/IVS and three cases with fetal CPS were enrolled between September 2016 and April 2018, and all cases were diagnosed with severe right ventricular dysplasia and growth arrest by fetal echocardiogram. Parameters of right heart structure development and hemodynamics from echocardiography included tricuspid /mitral annulus ratio (TV/MV), right ventricle/left ventricle long-axis ratio (RV/LV), tricuspid valve inflow duration/cardiac cycle ratio (TVI/CC), degree of tricuspid regurgitation (TR), blood flow direction of arterial duct and ductus venosus. FPV procedure was performed trans-abdominally under ultrasound-guidance. Echocardiography was performed post-procedure immediately and every 2-4 weeks until delivery. Results Seven FPV have been performed in the five fetuses with PA/IVS or CPS. The median gestational age at the time of FPV was 28 weeks. From technical perspective, pulmonary balloon valvuloplasty was successfully performed in all cases. The opening of pulmonary valve improved in these five cases in 2-4 weeks. However, progressive restenosis was detected in four fetuses during advancing gestation and re-atresia occurred in two PA/IVS cases at 36 weeks and 37 weeks gestation, respectively. The growth trajectories of TV/MV, RV/LV, and $\mathrm{TVI} / \mathrm{CC}$ improved in the first weeks, and then slowed down along with the pulmonary valve restenosis. All fetuses were born alive and underwent postnatal interventions, including pulmonary balloon valvuloplasty in 3 cases and surgical procedures in 2 cases. During the follow-up, three fetuses became biventricular, one case became one and a half ventricular at one year of age and the other one died of neonatal infection. Conclusion FPV is feasible and safe for fetuses during the second and third trimester of pregnancy. PV restenosis may occur as pregnancy advances, but overall, FPV still improved the growth trajectories of fetal right heart structures and has the potential to alter the natural history of PA/IVS and CPS.

\section{Background}

Pulmonary atresia with intact ventricular septum (PA/IVS) or critical pulmonary stenosis (CPS) carries a significant morbidity and mortality risk for fetuses and neonates. The incidence of congenital heart defect in pre- and post-natal series are different, with $5 \%$ and $1-3 \%$, respectively. ${ }^{[1]}$ PA/IVS or CPS is a morphologically heterogeneous lesion characterized by variable dimensions of right ventricle (RV) and tricuspid valve (TV), and varies from a normal size to a variable degree of hypoplasia. In addition, PA/IVS or CPS is commonly associated with coronary circulation anomalies. Notably, $10 \%$ of fetuses with CPS will progress to a complete atresia and PA/IVS will worsen during fetal life. ${ }^{[2,3]}$ Furthermore, small right heart will progress into a major degree hypoplasia.

Previous studies have demonstrated that fetal pulmonary valvuloplasty (FPV) is a feasible approach, which may promote right heart growth and improve fetal hemodynamics, thus resulting in biventricular circulation. ${ }^{[4-9]}$ Compared to Europe and US, the prevalence of PS is slightly higher in Asian populations, 
with a steady increase over time. ${ }^{[10]}$ Herein, we report the first series of FPV study in China. The aim of our study is to share our initial experience regarding case selection, technical feasibility, and post-FPV outcome.

\section{Methods}

\section{Cases selection}

Between September 2016 and April 2018, five fetuses underwent FPV in our center. Two cases were diagnosed as PA/IVS and three were CPS with severe right ventricular dysplasia by fetal echocardiography evaluation. Parameters of right ventricle development and hemodynamics included tricuspid/mitral annulus ratio (TV/MV), right ventricle/left ventricle long-axis ratio (RV/LV), tricuspid valve inflow duration/cardiac cycle ratio (TVI/CC), degree and velocity of tricuspid regurgitation (TR), blood flow direction of arterial duct and ductus venosus. These parameters, especially $T V / M V, R V / L V, T V I / C C$, were monitored every 2-4 weeks. All fetal echocardiography were done by the same experienced pediatric cardiologist.

The criteria published by Tulzer et al in 2016 was used in our current study to select fetuses for FPV. [11] The inclusion criteria were as follows: 1) either a membranous PA or a CPS with an intact ventricular septum, 2) an identifiable but small RV with supra-systemic pressure as assessed by the velocity of TR jet $2.5 \mathrm{~m} / \mathrm{s}, 3) \mathrm{RV}$ growth arrest within 3-4 weeks, and 4) retrograde flow in ductus arteriosus. The exclusion criteria were as follows: muscular atresia of right ventricular outflow tract obstruction, severe TR with low velocity and presence of large RV sinusoid.

The cutoff values of measurements published by Roman et al in 2007 were used to predict postnatal outcome, ${ }^{[12]}$ which included TV/MV $<0.7, \mathrm{RV} / \mathrm{LV}<0.6, \mathrm{TV} \mathrm{I} / \mathrm{CC}<0.315$ and the presence of RV sinusoids. In specific, if three out of the above four indicators were satisfied, the sensitivity and specificity to predict univentricular outcome was $100 \%$ and $75 \%$, respectively. The five cases selected in our current study was completely or partially qualified for the criteria.

The study was approved by Guangdong General Hospital Ethics Committee (Yue Medical Ethics 2016 NO. 10) and informed consent were obtained before FPV procedure.

\section{Fetal pulmonary valvuloplasty}

All FPVs procedure were under ultrasound-guidance and performed trans-abdominally as described in previous studies. ${ }^{[11]}$ (Figure 1a-d) The mothers were under general anesthesia during the operations. We used an 18 or 19 gauge needle (Cook) and a $4 \mathrm{~mm}$ coronary balloon catheter (Boston Scientific) (the largest size through an 18 gauge needle) for PV puncture and dilatation. Technical success is defined as successful passage and inflation of a dilated balloon across the pulmonary valve. Echocardiography was 
performed to observe subsequent improvement in antegrade flow. Fetal complications (pericardial effusion and bradycardia) during the procedure were monitored. Pericardiocentesis was performed immediately if hemodynamic compromise occurred. If persistent bradycardia developed, epinephrine was administered (according to estimated fetal weight) into fetal left heart or injected via maternal vein in case of emergency. During the first attempt, if technical failures or severe complication occurred, procedure would be discontinued and second attempt was performed in the next day.

\section{Post-FPV follow-up and postnatal outcome}

After the procedure, mother was hospitalized for two to three days. The fetus was assessed by fetal echocardiography later in the same day of FPV procedure as well as the day before discharge. Patients were followed at our center. Echocardiography was performed to evaluate the opening of pulmonary valve, right ventricle growth (Figure 2a-d) and hemodynamics status change every 2-4 weeks by the same experienced pediatric cardiologist until fetus delivery. After delivery, all fetuses were managed as neonates with PA/IVS or CPS.

\section{Results}

\section{Fetal pulmonary valvuloplasty}

Among the five cases, one case was PA/IVS, which was completely matched the criteria for a univentricular outcome and the other four were partially matched the criteria. Seven FPV procedures have been performed in the five cases. Three cases were at 28 weeks gestational age and two were at 30 weeks. From technical perspective, pulmonary balloon valvuloplasty were successfully performed in these five cases. The balloon to pulmonary valve ratio was $0.77-0.82$. There were no fetal deaths. One case with pericardial effusion underwent pericardiocentesis. Five cases had persistent severe bradycardia, and four were treated with both maternal intravenous infusion and fetal intra-cardiac injection of epinephrine, and the one only received maternal intravenous infusion of epinephrine (Table 1). There were no complications from maternal side.

\section{Post-FPV effects in utero}

All cases were followed in our center. Parameters of right ventricle development and hemodynamics before and after FPV (1-4weeks and 5-8weeks) are shown in Table 2. The improvement of PV opening was observed in all cases at 1-4 weeks post-FPV. However, restenosis was detected in four fetuses during advancing gestation and re-atresia occurred in two PA/IVS cases ( $\nabla 1$ and $\nabla 4$ ) at 36 weeks and 37 weeks gestation, respectively. The biggest change of TV/MV, RV/LV, and TVI/CC occurred in the first 1-4 weeks post-FPV and then slowed down along with PV restenosis. The growth trajectories of TV/MV, RV/LV, and $\mathrm{TVI} / \mathrm{CC}$ are illustrated in Figure $3 a-c$. The hemodynamics were stable during the intrauterine course. The 
direction of blood flow through the arterial duct changed to bidirectional in three cases, and the ductus venosus flow improved in two cases (Table 2).

\section{Postnatal outcome}

All fetuses were born alive and underwent postnatal interventions, including pulmonary balloon valvuloplasty in 3 cases and surgical procedures in 2 cases. Follow- up time ranged from 0.42-2.00 years. All postnatal procedures and outcome are listed in Table 1. Two PA/IVS cases with PV re-atresia underwent pulmonary valve commissurotomy and modified Blalock-Taussig shunt (B-T shunt) on the $8^{\text {th }}$ $(\otimes 1)$ and $32^{\text {th }}(\nabla 4)$ day, respectively. One of the cases $(\otimes 1)$, who also fulfilled $3 / 4$ parameters of the criteria for a univentricular outcome, had a bidirectional Glenn shunt and became one and a half ventricular circulation at one year old due to the small RV and TV dysplastic, and the other case ( $\mathbb{4} 4$ ) died on the $37^{\text {th }}$ day due to neonatal infection and uncontrolled hemodynamic instability despite with a well-size RV and underwent an emergency postnatal surgery. All other three fetuses underwent transcutaneous pulmonary balloon valvuloplasty in neonatal period and became biventricular.

\section{Discussion}

Since the first case of fetal cardiac intervention appeared in 1991, 50 more FPV cases for PA/IVS or CPS have been reported. There is evidence that restoration of normal flow promotes growth and reduction in ventricular pressure enables normal development and function. ${ }^{[13-15]}$ It is therefore reasonable to improve fetal cardiac intervention for PA/IVS and CPS. However, based on the potential risk of FPV, two major points should be mentioned: first, select appropriate cases, which may be probably benefited from FPV; and second, consider the feasibility, safety, and outcomes of FPV, aiming to better balance the risks and benefits of each individual case.

\section{Case selection}

So far, selection of appropriate candidates for FPV remains controversy. It is acceptable and rational to perform FPV for PA/IVS or CPS complicated by severe right heart failure during the second trimester because timely FPV can improve fetal hydrops and avoid fetal demise. Although most of the PA/IVS and CPS fetuses were without significant fetal hydrops in the compensatory stage, FPV remains necessary because postnatal procedure cannot promote catch-up of fetus growth. ${ }^{[16]}$ Previous animal experiments show that increased pre- and after-load leads to myocytes proliferation and hyperplasia. ${ }^{[17-19]}$ The ability for myocytes proliferation disappears shortly after birth, and myocardium will respond with hypertrophy instead of hyperplasia. RV will grow corresponding to body size growth after neonatal procedure. Therefore, FPV is an important approach to improve prenatal RV growth and avoid postnatal univentricular outcome. 
In the absence of large RV sinusoid fistulae or a muscular atresia of right ventricular outflow tract, RV and TV size at birth are the major determinants of a biventricular outcome. A "hypoplastic" but still "salvageable" right heart structure is one of the most important aspects of FPV case selection at the second trimester. Fetuses with an unidentifiable RV and coronary anomalies are "unsalvageable", which could not restore biventricular circulation regardless of prenatal intervention. On the other hand, fetuses with a well RV size can be reserved for intervention after birth. Obviously, the above two conditions are not good candidates for FPV. Between these two extreme conditions are fetuses with an identifiable but variable right heart hypoplasia. This group includes the most appropriate candidates for FPV. Several studies have reported the prediction of a univentricular outcome in fetuses with PA/IVS and CPS. ${ }^{[6,12,20-}$ ${ }^{22]}$ Due to lack of effective evaluation of Z-score in China, we adopted a frequently used four-criteria scoring system to predict postnatal outcome, ${ }^{[12]}$ which includes $T V / M V$ ratio $<0.7, R V / L V$ length ratio $<0.6$, $\mathrm{TVI} / \mathrm{CC}<31.5 \%$ and presence of RV sinusoids. After excluding the cases with large RV sinusoid, ideal candidates for FPV should match the other three criteria to justify fetal treatment. In our study, one fetus with PA/IVS matched the criteria for a univentricular outcome (3/4 parameters), and the other four fetuses were featured with the above parameters approximate to the cutoff values. Fetal echocardiography was performed to closely monitor RV growth. If RV does not show any increase in size over a period of 2-4 weeks, a spontaneous reversal of this process is unlikely and FPV is considered to open the PV.

\section{Technical considerations}

Although the experience with FPV is still limited to few case reports and small case series, previous studies show that FPV in the mid-gestation is technically feasible by an experienced team. ${ }^{[4-6,9,23]}$ The technical success rate approximated to that of fetal aortic valvuloplasty, about $70-80 \% .{ }^{[5,6]}$ In 2018 , the group of Children's Heart Center in Linz reported the largest series experience of 35 attempted FPV in 23 fetuses. ${ }^{[23]}$ Seventeen cases were underwent successful procedure, and no procedure related fetal deaths and maternal complication occurred. However, a hypoplastic RV with a narrow, short, curved segment below the valve makes FPV a technically challenging procedure. We considered fetal position and an experienced team in coordinating imaging, needling, catheter manipulation and managing complications are the key factors influencing success rate.

During the procedure, the most common fetal complications are episode of severe bradycardia and pericardial effusion. However, timely and proper therapy can effectively avoid intra-uterine fetal death. It was demonstrated that RV interventions are better tolerated than LV interventions, probably due to without coronary arteries would be occluded during balloon inflation in RV. ${ }^{[6]}$ FPV was successfully done in our five cases, and most of our experiences are similar to those gaining from previous studies. In all five cases, severe bradycardia occurred when the needle was puncturing the right ventricular outflow track or when balloon catheter was dilating PV. We found epinephrine administered via maternal peripheral vein could increase fetal heart rate, rendering more time for intra-cardiac epinephrine injection. Our five 
fetuses with persistent bradycardia were all injected epinephrine via maternal peripheral vein under anesthesiologist monitoring, and one fetus recovered instantly before cardiac puncture for intra-cardiac epinephrine injection. In addition, large pericardial effusion with sign of hemodynamic compromise occurred in one fetus, which was underwent pericardiocentesis immediately. Small pericardial effusion in four fetuses resolved on its own 3-5 days later.

\section{Outcome}

Previous studies have showed that pulmonary valve underwent restenosis post-procedure during advancing gestation. ${ }^{[23]}$ In our study, we also observed four fetuses underwent restenosis and two fetuses underwent re-atresia in near-term pregnancy, respectively. The potential explanations were on the one hand, we performed the procedure in a late gestational age (28-30 week), and on the other hand, we used a small balloon to dilate PV (balloon/PV diameter ratio 0.77-0.82). In general, balloon size should be at least $10-20 \%$ larger than the valve diameter. ${ }^{[11]}$ However, with the current available equipment, the largest size of balloon is $4 \mathrm{~mm}$, which is comparable to an $18 \mathrm{G}$ needle. Larger needles will increase the risk of trauma to amniotic membranes as well as to the fetal heart, resulting in bradycardia, thrombus and pericardial effusions. The other explanation might be due to low RV stroke volume, which was associated with hypertrophic, restrictive RV and dysplastic TV. TV dysplasia with tricuspid stenosis could have contributed to PV re-atresia and slower RV improvement in the \#1 case. In this case, even FPV and postnatal procedure was conducted successfully, severe inflow obstruction still limited RV filling and pulmonary forward flow. Notably, pulmonary forward flow was a favorable factor for RV growth. Therefore, in echocardiography examination, besides measuring TV annulus, it is also important to evaluate the presence of thickened and fusional TV leaflets, restricted TV opening and TV inflow duration. PV restenosis may be unavoidable as pregnancy advanced, Tulzer et al. suggested that even the FPV is partially successful, a minor RV decompression is able to improve hemodynamics. ${ }^{[23]}$ Furthermore, restenosis mainly occurred in near-term pregnancy, FPV can still improve the growth trajectories of fetal RV structure in the early weeks and benefit some fetuses with PA/IVS and CPS. Meanwhile, in our study, the growth trajectories of TV/MV, RV/LV, AND TVI/CC were improved in the early weeks and then slowed down along with the restenosis, indicating that ventricular pressure reduction enabled improvement in ventricular filling, compliance and growth.

Fetal cardiac intervention should be considered as a palliative therapy. We were unable to eliminate the gradient across the pulmonary valve, especially in the last gestation stage. Normal RV size could not be achieved despite with successful FPV. One or more additional postnatal procedures are required for management of this defect after birth. In our study, all five fetuses underwent postnatal transcatheter or surgical interventions. Two fetuses with pulmonary valve re-atresia underwent surgical procedures after birth, and among them, one with TV stenosis became one and a half ventricular circulation at one year old, and the other one with a well-size RV died of neonatal infection. Three fetuses underwent transcutaneous pulmonary balloon valvuloplasty in neonatal period and became biventricular. 


\section{Limitations}

This study is limited by its small sample size and non-randomized design. In addition, there are several issues have to be clarified and improved before FPV can be routinely applied to fetuses with pulmonary atresia and stenosis. For example, better understanding the nature history of PA/IVS or CPS could help us unify the case selection criteria. In order to minimize risks and optimize technical success, improvements in needles, balloon, and imaging should also be achieved.

\section{Conclusions}

In conclusion, this is the first case series reported from China, and we herein reported our initial experiences. In our study, we consider that FPV is feasible and safe. Although PV restenosis occurs as pregnancy advanced, FPV still improve the growth trajectories of fetal RV structure and benefit some fetuses with PA/IVS and CPS. We believe that there is a place for FPV given that an accurate cases selection is made and the procedure is performed by an experienced team.

\section{Abbreviations}

FPV: Fetal pulmonary valvuloplasty; PA/IVS: Pulmonary atresia with intact ventricular septum (PA/IVS); CPS: critical pulmonary stenosis; TV: Tricuspid valve; MV: Mitral valve; RV: Right ventricle; LV: Left ventricle; PV: Pulmonary valve; AV: Aortic valve; TV/MV: Tricuspid /mitral annulus ratio; RV/LV: Right ventricle/left ventricle long-axis ratio; TVI/CC: Tricuspid valve inflow duration/cardiac cycle ratio; TR: Tricuspid regurgitation; AD: Arterial duct; DV: Ductus venosus; Sv: Severe; Rv: Reversed; Mx: Mixed; Ab: Absent; At: Antegrade

\section{Declarations}

\section{Acknowledgements}

Our five FPV procedures were all performed under the instruction of Dr. Tulzer and Dr. Arzt from Children's Heart Center in Linz.

\section{Funding}

No. 
The data sets used and/or analyzed during the current study are available from the corresponding author on reasonable request.

\section{Authors' contribution}

The manuscript was drafted by PCC, PW, ZCB and critically revised by all authors. The ideal of the work was conceived by LYF, ZJ. FPV procedure was performed by ZZW, ZX, HFZ, SYX, WS. Access to data was provided by PCC, PW. All author read and agree for the manuscript to be published.

\section{Ethics approval and consent to participate}

The study was approved by Guangdong General Hospital Ethics Committee (Yue Medical Ethics 2016 NO. 10) and informed consent were obtained before FPV procedure.

\section{Consent for publication}

All authors agree to submit and publish this paper.

\section{Competing interests}

The authors declare that they have no competing interests.

\section{Author details}

1 Department of Maternal-Fetal Cardiology, Guangdong Cardiovascular Institute, Guangdong General Hospital, Guangdong Academy of Medical Sciences, Guangdong Province Key Laboratory of Structural Heart Disease, Guangzhou, Guangdong, 510080, China. 2 Department of Pediatric Cardiology, Guangdong Cardiovascular Institute, Guangdong General Hospital, Guangdong Academy of Medical Sciences, Guangdong Province Key Laboratory of Structural Heart Disease, Guangzhou, Guangdong, 510080, China. 3 Department of Obstetrics, Guangdong Cardiovascular Institute, Guangdong General Hospital, Guangdong Academy of Medical Sciences, Guangdong Province Key Laboratory of Structural Heart Disease, Guangzhou, Guangdong, 510080, China. 4 Department of Neonatology, Guangdong Cardiovascular Institute, Guangdong General Hospital, Guangdong Academy of Medical Sciences, Guangdong Province Key Laboratory of Structural Heart Disease, Guangzhou, Guangdong, 510080, China. 5 Department of Anesthesiology, Guangdong Cardiovascular Institute, Guangdong General 
Hospital, Guangdong Academy of Medical Sciences, Guangdong Province Key Laboratory of Structural Heart Disease, Guangzhou, Guangdong, 510080, China. 6 Department of Cardiac surgery, Guangdong Cardiovascular Institute, Guangdong General Hospital, Guangdong Academy of Medical Sciences, Guangdong Province Key Laboratory of Structural Heart Disease, Guangzhou, Guangdong, 510080, China

\section{References}

[1] Todros T, Paladini D, Chiappa E, et al. Pulmonary stenosis and atresia with intact ventricular septum during prenatal life. Ultrasound Obstet Gynecol. 2003. 21(3): 228-33.

[2] Rice MJ, McDonald RW, Reller MD. Progressive pulmonary stenosis in the fetus: two case reports. Am J Perinatol. 1993. 10(6): 424-7.

[3] Todros T, Presbitero P, Gaglioti P, Demarie D. Pulmonary stenosis with intact ventricular septum: documentation of development of the lesion echocardiographically during fetal life. Int J Cardiol. 1988. 19(3): 355-62.

[4] Tulzer G, Arzt W, Franklin RC, Loughna PV, Mair R, Gardiner HM. Fetal pulmonary valvuloplasty for critical pulmonary stenosis or atresia with intact septum. Lancet. 2002. 360(9345): 1567-8.

[5] Tworetzky W, McElhinney DB, Marx GR, et al. In utero valvuloplasty for pulmonary atresia with hypoplastic right ventricle: techniques and outcomes. Pediatrics. 2009. 124(3): e510-8.

[6] Gómez ME, Herraiz I, Mendoza A, Galindo A. Fetal intervention in right outflow tract obstructive disease: selection of candidates and results. Cardiol Res Pract. 2012. 2012: 592403.

[7] Pedra SF, Peralta CF, CAC P. Future Directions of Fetal Interventions in Congenital Heart Disease. Interv Cardiol Clin. 2013. 2(1): 1-10.

[8] Moon-Grady AJ, Morris SA, Belfort M, et al. International Fetal Cardiac Intervention Registry: A Worldwide Collaborative Description and Preliminary Outcomes. J Am Coll Cardiol. 2015. 66(4): 388-99.

[9] Galindo A, Gutiérrez-Larraya F, Velasco JM, de la Fuente P. Pulmonary balloon valvuloplasty in a fetus with critical pulmonary stenosis/atresia with intact ventricular septum and heart failure. Fetal Diagn Ther. 2006. 21(1): 100-4.

[10] Mitchell B, Mhlongo M. The diagnosis and management of congenital pulmonary valve stenosis. SA Heart, 2018, 15: 36-45.

[11] Tulzer G, Butera G. Fetal and hybrid procedures in congenital heart diseases. Switzerland: Springer International Publishing, 2016: 84-92.

[12] Roman KS, Fouron JC, Nii M, Smallhorn JF, Chaturvedi R, Jaeggi ET. Determinants of outcome in fetal pulmonary valve stenosis or atresia with intact ventricular septum. Am J Cardiol. 2007. 99(5): 699- 
703.

[13] Hanséus K, Björkhem G, Lundström NR, Laurin S. Cross-sectional echocardiographic measurements of right ventricular size and growth in patients with pulmonary atresia and intact ventricular septum. Pediatr Cardiol. 1991. 12(3): 135-42.

[14] Tworetzky W, Wilkins-Haug L, Jennings RW, et al. Balloon dilation of severe aortic stenosis in the fetus: potential for prevention of hypoplastic left heart syndrome: candidate selection, technique, and results of successful intervention. Circulation. 2004. 110(15): 2125-31.

[15] Tulzer G, Gardiner H. Cardiac interventions in the fetus: potential for right-sided lesions. Fetal interventions in right heart disease. Progress in Pediatric Cardiology, 2006, 22(1), 79-83.

[16] Ovaert C, Qureshi SA, Rosenthal E, Baker EJ, Tynan M. Growth of the right ventricle after successful transcatheter pulmonary valvotomy in neonates and infants with pulmonary atresia and intact ventricular septum. J Thorac Cardiovasc Surg. 1998. 115(5): 1055-62.

[17] Clark EB, Hu N, Frommelt P, Vandekieft GK, Dummett JL, Tomanek RJ. Effect of increased pressure on ventricular growth in stage 21 chick embryos. Am J Physiol. 1989. 257(1 Pt 2): H55-61.

[18] Saiki Y, Konig A, Waddell J, Rebeyka IM. Hemodynamic alteration by fetal surgery accelerates myocyte proliferation in fetal guinea pig hearts. Surgery. 1997. 122(2): 412-9.

[19] deAlmeida A, McQuinn T, Sedmera D. Increased ventricular preload is compensated by myocyte proliferation in normal and hypoplastic fetal chick left ventricle. Circ Res. 2007. 100(9): 1363-70.

[20] Salvin JW, McElhinney DB, Colan SD, et al. Fetal tricuspid valve size and growth as predictors of outcome in pulmonary atresia with intact ventricular septum. Pediatrics. 2006. 118(2): e415-20.

[21] Wohlmuth C, Tulzer G, Arzt W, Gitter R, Wertaschnigg D. Maternal aspects of fetal cardiac intervention. Ultrasound Obstet Gynecol. 2014. 44(5): 532-7.

[22] Gardiner HM, Belmar C, Tulzer G, et al. Morphologic and functional predictors of eventual circulation in the fetus with pulmonary atresia or critical pulmonary stenosis with intact septum. J Am Coll Cardiol. 2008. 51(13): 1299-308.

[23] Tulzer A, Arzt W, Gitter R, et al. Immediate effects and outcome of in-utero pulmonary valvuloplasty in fetuses with pulmonary atresia with intact ventricular septum or critical pulmonary stenosis. Ultrasound Obstet Gynecol. 2018. 52(2): 230-237.

\section{Tables}

Table 1 Echo data before and after FPV for the five cases 


\begin{tabular}{|c|c|c|c|c|c|c|}
\hline \multirow{2}{*}{\multicolumn{2}{|c|}{ Before FPV(1-2days) }} & \multirow[t]{2}{*}{ Case1 } & \multirow[t]{2}{*}{ Case2 } & \multirow[t]{2}{*}{ Case 3} & \multirow[t]{2}{*}{ Case 4} & \multirow[t]{2}{*}{ Case 5} \\
\hline & & & & & & \\
\hline \multirow[t]{4}{*}{$2 \mathrm{D}$} & $\mathrm{TV} / \mathrm{MV}$ & 0.56 & 0.7 & 0.71 & 0.85 & 0.77 \\
\hline & $\mathrm{RV} / \mathrm{LV}$ & 0.42 & 0.63 & 0.55 & 0.61 & 0.75 \\
\hline & PV/AV & 0.85 & 0.91 & 0.84 & 0.87 & 1.17 \\
\hline & TVI/CC & 0.26 & 0.35 & 0.4 & 0.43 & 0.38 \\
\hline \multirow[t]{4}{*}{ Flow } & TR Vmax (m/s) & Sv, 4.6 & Sv, 4.4 & Sv, 5.0 & Sv, 4.3 & Mild \\
\hline & $\mathrm{AD}$ & $\mathrm{Rv}$ & $\mathrm{Rv}$ & $\mathrm{Rv}$ & $\mathrm{Rv}$ & $\mathrm{Rv}$ \\
\hline & DV & $\mathrm{Rv}$ & $\mathrm{Rv}$ & $\mathrm{Rv}$ & $\mathrm{Rv}$ & $\mathrm{Rv}$ \\
\hline & PV Orifice (mm) & No & 1.3 & 1.6 & No & 2.3 \\
\hline \multicolumn{7}{|c|}{ After FPV (1-4week) } \\
\hline \multirow[t]{4}{*}{$2 \mathrm{D}$} & TV/MV & 0.56 & 0.75 & 0.81 & 0.85 & 0.86 \\
\hline & $\mathrm{RV} / \mathrm{LV}$ & 0.47 & 0.73 & 0.76 & 0.83 & 0.78 \\
\hline & PV/AV & 0.92 & 0.92 & 0.91 & 0.97 & 1.26 \\
\hline & TVI/CC & 0.3 & 0.4 & 0.44 & 0.46 & 0.45 \\
\hline \multirow[t]{4}{*}{ Flow } & TR Vmax (m/s) & Sv, 4.1 & Sv, 4.2 & Sv, 4.7 & Sv, 4.0 & Mild \\
\hline & $\mathrm{AD}$ & $\mathrm{Rv}$ & $\mathrm{Mx}$ & $\mathrm{Mx}$ & $\mathrm{Mx}$ & $\mathrm{Mx}$ \\
\hline & DV & $\mathrm{Rv}$ & $\mathrm{Ab}$ & $\mathrm{Rv}$ & $\mathrm{Rv}$ & At \\
\hline & PV Orifice (mm) & 2 & 3.3 & 3.6 & 2 & 3.4 \\
\hline \multicolumn{7}{|c|}{ After FPV (5-8week) } \\
\hline \multirow[t]{4}{*}{$2 \mathrm{D}$} & TV/MV & 0.59 & 0.8 & 0.86 & 0.98 & 0.93 \\
\hline & $\mathrm{RV} / \mathrm{LV}$ & 0.51 & 0.8 & 0.77 & 0.82 & 0.83 \\
\hline & PV/AV & 0.87 & 0.97 & 0.93 & 1.16 & 1.2 \\
\hline & TVI/CC & 0.32 & 0.42 & 0.44 & 0.44 & 0.46 \\
\hline \multirow[t]{4}{*}{ Flow } & TR Vmax (m/s) & Mod, 4.8 & Sv, 3.8 & $\mathrm{~Sv}, 4.5$ & Sv, 3.7 & Mild \\
\hline & $\mathrm{AD}$ & $\mathrm{Rv}$ & $\mathrm{Mx}$ & $\mathrm{Mx}$ & $\mathrm{Rv}$ & $\mathrm{Mx}$ \\
\hline & DV & $\mathrm{Rv}$ & $\mathrm{Rv}$ & $\mathrm{Rv}$ & $\mathrm{Rv}$ & At \\
\hline & PV Orifice (mm) & No & 3.5 & 3.3 & No & 2.6 \\
\hline
\end{tabular}

TV: tricuspid valve; MV: mitral valve; RV: right ventricle; LV: left ventricle; PV: pulmonary valve; AV: aortic valve; TR: tricuspid regurgitation; AD: arterial duct; DV: ductus venosus; Sv: severe; Rv: reversed; Mx: mixed; Ab: absent; At: antegrade 
Table 2 Before and after FPV and postnatal characteristics of the five cases

\begin{tabular}{|c|c|c|c|c|c|}
\hline & Case1 & Case2 & Case 3 & Case 4 & Case 5 \\
\hline Anatomy & PA/IVS, TS & CPS & CPS & PA/IVS & CPS \\
\hline $\begin{array}{l}\text { GA at } \\
\text { diagnosis/at FPV } \\
\text { (week) }\end{array}$ & $24 / 28$ & $26 / 28$ & $24 / 30$ & $23 / 30$ & $24 / 28$ \\
\hline $\begin{array}{l}\text { Number of } \\
\text { Attempt }\end{array}$ & 2 & 1 & 2 & 1 & 1 \\
\hline $\begin{array}{l}\text { Balloon/Valve } \\
\text { Ratio }\end{array}$ & 0.8 & 0.78 & 0.77 & 0.77 & 0.82 \\
\hline $\mathrm{PE}$ & $\begin{array}{l}\text { Mild, } \\
\text { No treatmeat }\end{array}$ & $\begin{array}{l}\text { Mild, } \\
\text { No treatmeat }\end{array}$ & $\begin{array}{l}\text { Mild, } \\
\text { No treatmeat }\end{array}$ & $\begin{array}{c}\text { Severe, } \\
\text { Pericardiocentesis }\end{array}$ & $\begin{array}{l}\text { Mild, } \\
\text { No treatmeat }\end{array}$ \\
\hline Bradycardia & $\begin{array}{c}\text { Yes, } \\
\text { Epinephrine } \\
\text { into LV }\end{array}$ & $\begin{array}{c}\text { Yes, } \\
\text { Epinephrine } \\
\text { IV }\end{array}$ & $\begin{array}{c}\text { Yes, } \\
\text { Epinephrine } \\
\text { into LV }\end{array}$ & $\begin{array}{l}\text { Yes, } \\
\text { Epinephrine } \\
\quad \text { into LA }\end{array}$ & $\begin{array}{l}\text { Yes, } \\
\text { Epinephrine } \\
\text { into LA }\end{array}$ \\
\hline $\begin{array}{l}\text { GA at Birth } \\
\text { (week) }\end{array}$ & 39 & 35 & 38 & 38 & 37 \\
\hline $\begin{array}{l}\text { Postnatal } \\
\text { procedure }\end{array}$ & $\begin{array}{l}\text { PV commissurotomy } \\
\text { and B-T Shunt (8D) } \\
\text { Glenn }(1 \mathrm{Y})\end{array}$ & PBPV (17D) & PBPV (10D) & $\begin{array}{l}\text { B-T Shunt (28D) } \\
\text { Death (37Y) }\end{array}$ & PBPV(13D) \\
\hline $\begin{array}{l}\text { Follow up } \\
\text { (years) }\end{array}$ & 2 & 1.33 & 0.92 & NA & 0.42 \\
\hline
\end{tabular}

Figures 

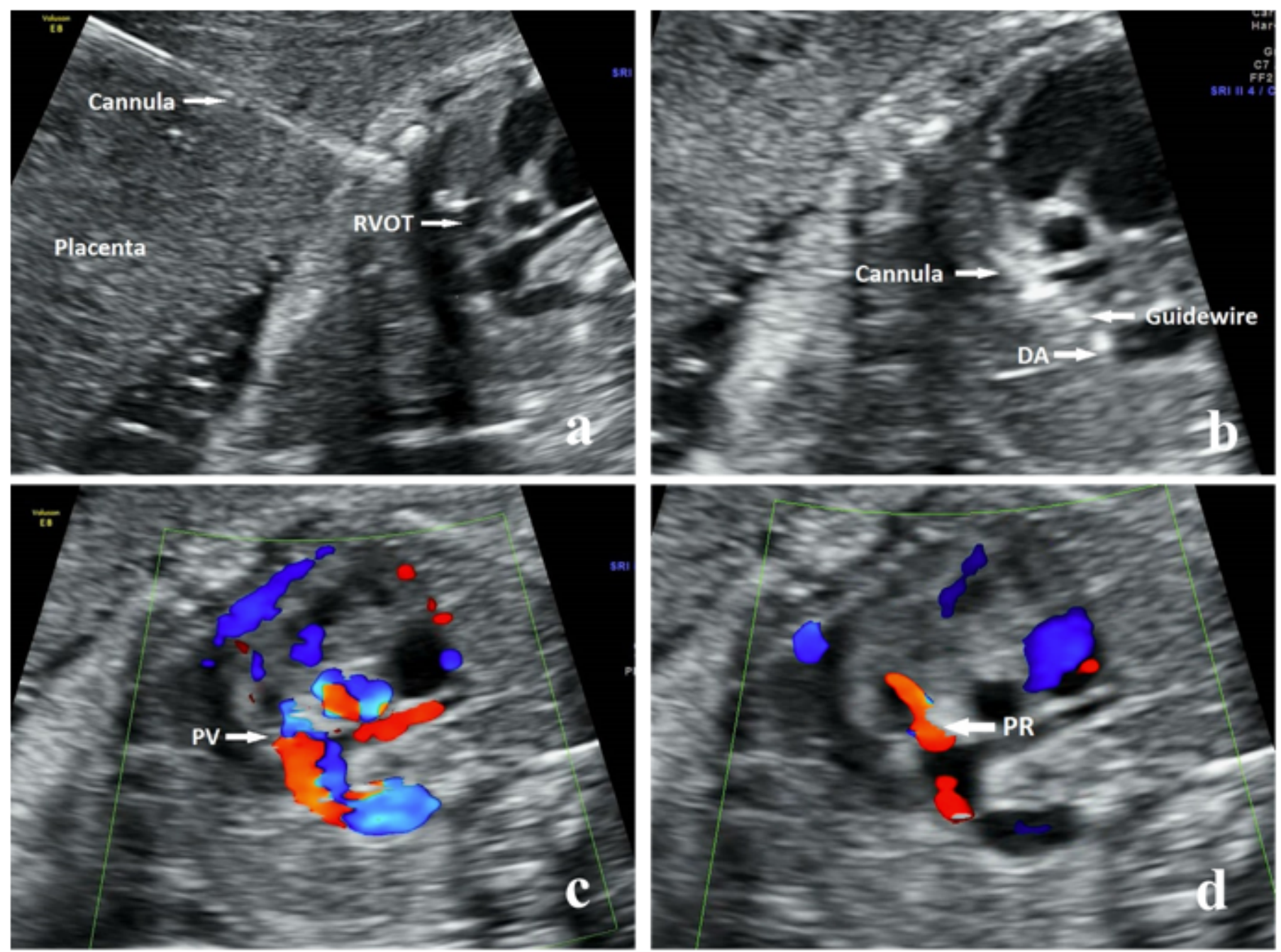

Figure 1

1a-d Representative images of echocardiography-guided PFV for fetus with PA/IVS b. Cannula was in the right ventricular outflow tract; $b$. Guidewire was across pulmonary valve and placed in ductus arteriosus; c. After FPV, ante-grade flow across pulmonary valve; d. Pulmonary regurgitation appeared. 

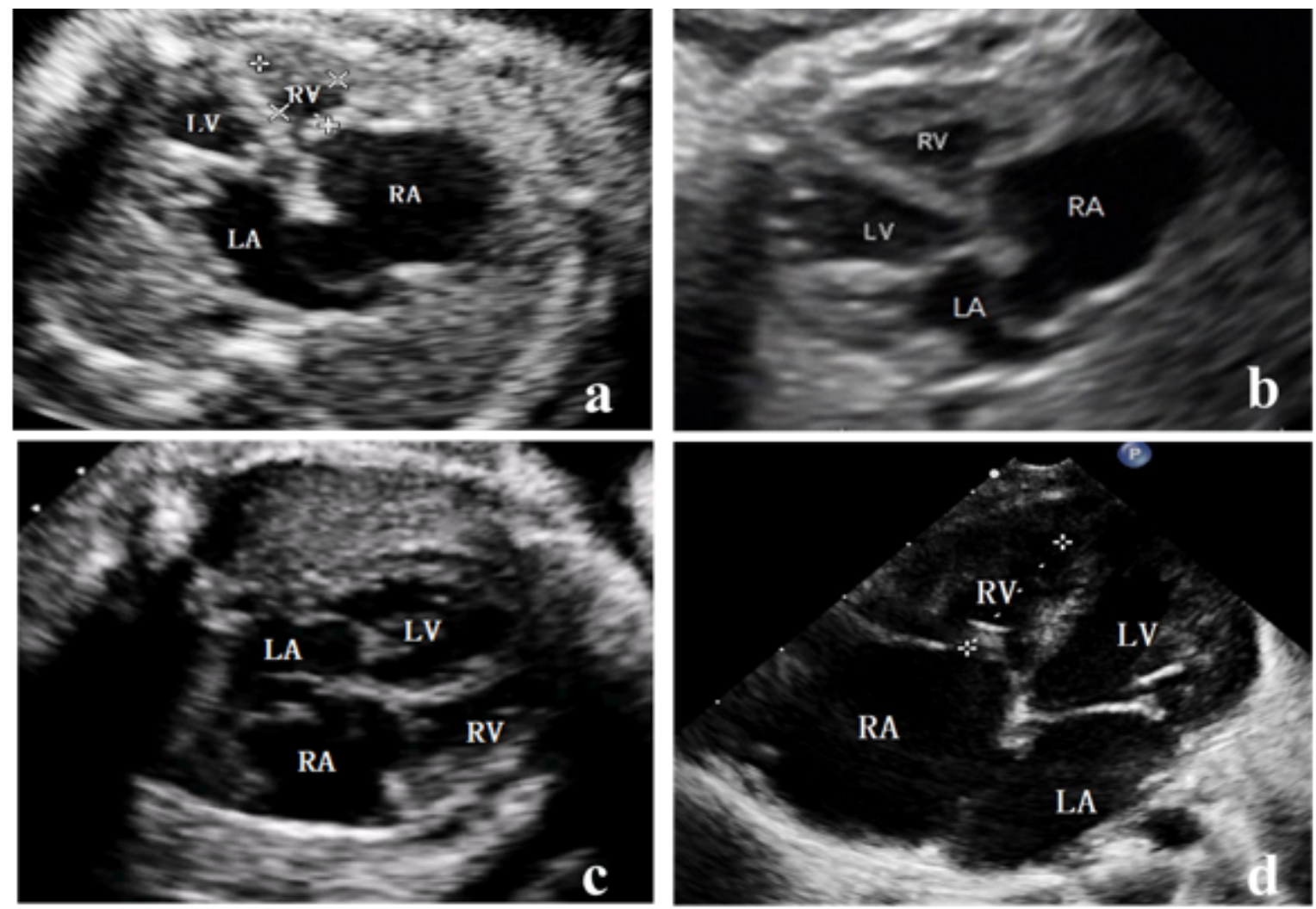

\section{Figure 2}

2a-d Four-chamber view of Case 2 before FPV (a), 2 weeks (b) and 6 weeks (c) after FPV, and 2 days after birth (d) RV/LV ratio changed from 0.63 to 0.80 . LA: left atrium, LV: left ventricle, RA: right atrium, RV: right ventricle.

a

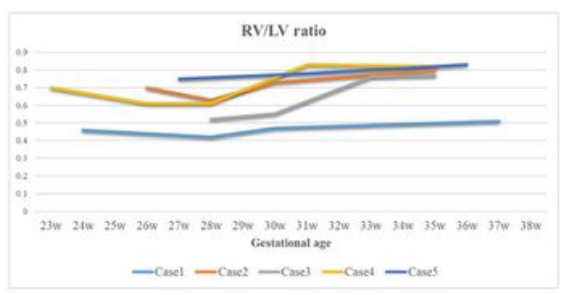

b

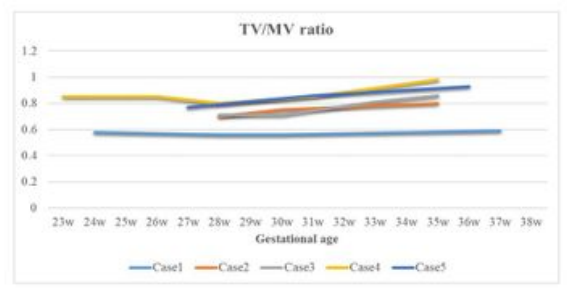

C

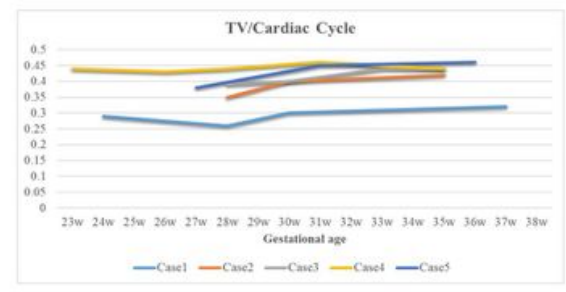

\section{Figure 3}

3a-c Growth trajectories of right heart structure TV/MV, RV/LV, and TVI/CC improved in the first weeks, and then reached a plateau along with the pulmonary valve restenosis 